Article

\title{
Triple-Mode Switched-Inductor-Capacitor DC-DC Buck Converter with Reusable Flying Capacitor and Bang-Bang Zero-Current Detector for Wide Load Current Range
}

\author{
Jongbeom Baek ${ }^{1}$, Hyung-Min Lee ${ }^{2}\left(\mathbb{D}\right.$ and Se-Un Shin ${ }^{3, *(1)}$ \\ 1 School of Electrical Engineering, Korea Advanced Institute of Science and Technology, Daejeon 34141, Korea; \\ baekjb@kaist.ac.kr \\ 2 School of Electrical Engineering, Korea University, Seoul 02841, Korea; hyungmin@korea.ac.kr \\ 3 School of Electronics and Electrical Engineering, Dankook University, Yongin 16890, Korea \\ * Correspondence: seuns@dankook.ac.kr; Tel.: +82-41-550-3592
}

Received: 20 June 2020; Accepted: 24 July 2020; Published: 27 July 2020

\begin{abstract}
Although the capacity of a battery with a small form factor is extremely low, demand for long usage time of Internet of Things (IoT) products is increasing. Owing to this limitation of the battery, power management integrated circuits (PMICs) are used for extending the battery usage time with high efficiency. In particular, since IoT devices are mostly in the sleep mode in the idle state, PMICs should achieve high efficiency for ultralight loads in the sleep mode as well as for heavy loads in the active mode. In this paper, an accurate bang-bang zero-current detector (to prevent a reverse inductor current) and a triple-mode switched inductor-capacitor dc-dc buck converter with a reusable flying capacitor are presented; these techniques can maintain high efficiency over a wide load current range. The proposed buck converter was fabricated in a $0.18-\mu \mathrm{m} 1 \mathrm{P} 4 \mathrm{M}$ CMOS process. A power conversion efficiency exceeding $85 \%$ was achieved in the load range of $100 \mu \mathrm{A}$ to $300 \mathrm{~mA}$.
\end{abstract}

Keywords: buck converter; discontinuous conduction mode; flying capacitor; power management integrated circuits; zero-current detector

\section{Introduction}

Recently, demand for Internet of Things (IoT) devices with a small form factor has been rapidly increasing. The limited capacity of their small battery results in a significantly short usage time of the devices. Accordingly, power management integrated circuits (PMICs) are used for increasing the usage time of IoT devices. In particular, PMICs in IoT devices should have high efficiency for a wide load current range, ranging from heavy load conditions when the device is active to light load conditions when the device is in the idle state consuming standby power.

Figure 1a shows the proportion of different types of power losses across the load current range when the power stage with a constant input source is implemented on-chip and the operating switching frequency is fixed-conduction loss, switching loss, and controller loss-in switching type dc-dc converters among PMICs, such as a switched-inductor (SI) converter and a switched-capacitor (SC) converter. It shows that the ratio of the total power losses is strongly dependent on the load current level. Therefore, a suitable control method for minimizing power losses in different load conditions is required. As shown in Figure 1b, an SI converter involving continuous conduction mode (CCM) control shows high efficiency in heavy load current conditions since conduction loss is dominant [1-4]. However, as the load current decreases, a reverse current flowing through the inductor is generated. The SI converter should then operate in the discontinuous conduction mode (DCM) rather than the CCM. 
Additionally, when variable frequency modulation (VFM) is used, the SI converter with DCM operation can reduce the switching loss to achieve high efficiency for light load current conditions [1,2,5-7]. For the maximum efficiency of the SI converter operating in the DCM, a high-precision zero-current detector $(\mathrm{ZCD})$ is necessary to prevent reverse current through the inductor.

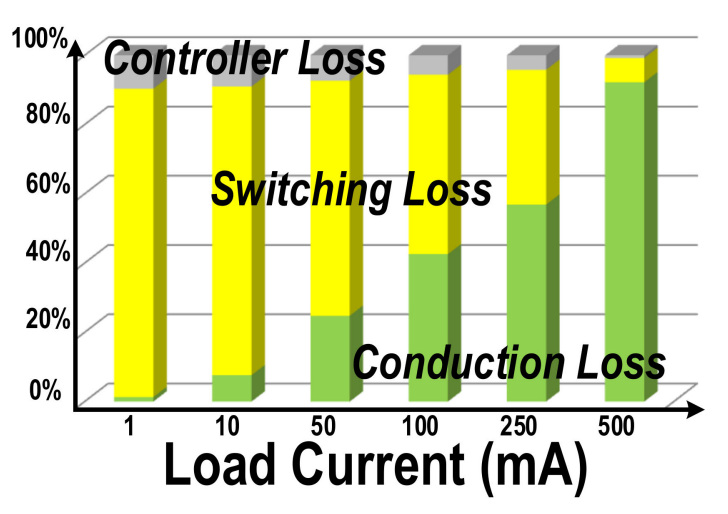

(a)

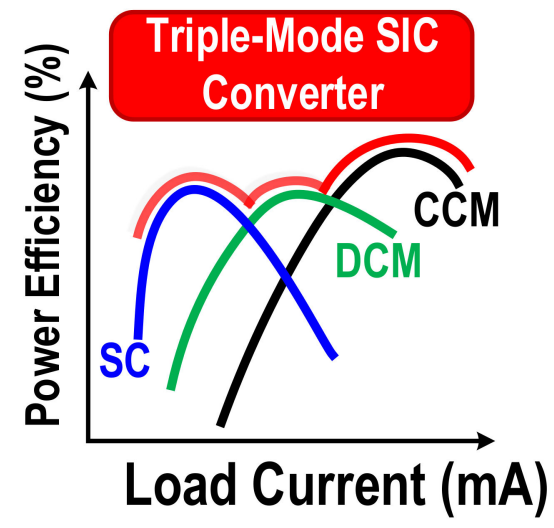

(b)

Figure 1. (a) Ratio of power losses in the switching type power converter with different load current conditions and (b) efficiency comparison plot in a different mode of the converter.

Despite the SI converter operating in the DCM, it has a performance limit in ultralight load current conditions [7]. The SC converter, which is another type of PMICs, uses only capacitors as energy transfer media, and no inductor is involved. Owing to its low controller and switching losses, it exhibits better efficiency than the SI converter in ultralight load current conditions [8-12]. Even if the SC converter is also designed efficiently under heavy load conditions, a large number of large capacitors must be mounted on the outside of the chip, which can take up more PCB size than the SI converter with a single inductor. In addition, because of a predefined conversion gain, the efficiency of the SC converter can be significantly decreased as the input voltage changes. Accordingly, if a single converter can be designed to operate as an SI and an SC converter adaptively, high power efficiency can be achieved over the wide load current range for IoT devices, extending the battery usage time.

This paper, which is an expanded version of [13], presents a triple-mode switched inductorcapacitor dc-dc buck converter that offers the advantages of both aforementioned converters. Figure $2 \mathrm{a}$ shows the conventional SI converter with a proportional-integral-derivative (PID) compensator requiring a large compensation-capacitor $\left(C_{C}\right)$ for pulse width modulation (PWM). As shown in Figure $2 \mathrm{~b}$, the proposed switched inductor-capacitor (SIC) converter reuses the $\mathrm{Cc}$ as a flying capacitor of the SC converter for the ultra-light load condition. Furthermore, a high-precision bang-bang ZCD is proposed for enhancing the power conversion efficiency when the SI converter operates in the DCM.

The rest of this paper is organized as follows. Section 2 describes the overall architecture of the triple-mode SIC dc-dc buck converter. Section 3 proposes a bang-bang zero current detector (BB-ZCD) that operates in the DCM. Section 4 presents measurements and performance comparisons and Section 5 provides the conclusions in brief. 


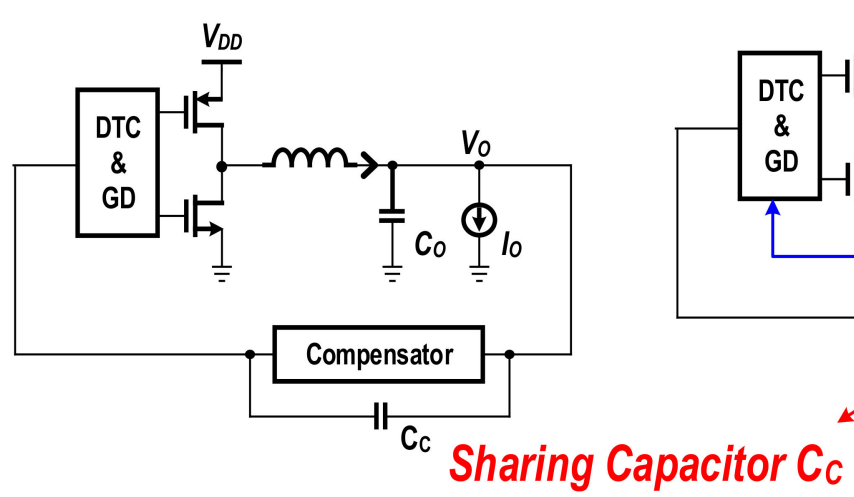

(a)

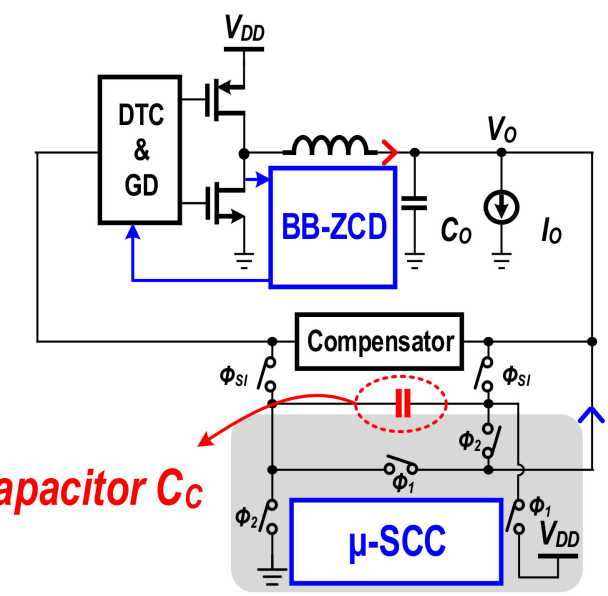

(b)

Figure 2. (a) Conventional dc-dc buck converter and (b) the proposed triple-mode switched inductorcapacitor (SIC) dc-dc buck converter with a reusable flying capacitor and a bang-bang zero-current detector.

\section{Tripe-Mode Structure}

Figure 3 shows the overall structure of the proposed SIC dc-dc buck converter. As described above, since the ratio of the total power losses in the converter depends on the load current level, the proposed converter changes operating modes according to the load current $\left(I_{O}\right)$. A mode selector (MS) manages and changes the operating mode as shown in Table 1. When the SIC converter operates as an SI converter along with the main power switches $M_{P}$ and $M_{N}$, and an inductor $(L)$ in either the CCM or the DCM, conventional peak current mode control is adopted. As a heavy load current is defined as a load current exceeding $20 \mathrm{~mA}$, the converter can reduce dominant conduction losses in this heavy load current conditions if it is allowed to operate in the CCM with a fixed switching frequency. For a load current range from 2 to $20 \mathrm{~mA}$, which corresponds to light load current conditions, VFM is applied in the DCM to reduce switching losses. Moreover, the BB-ZCD is proposed to enhance the power conversion efficiency at light load condition. In ultralight load conditions, corresponding to a current less than $2 \mathrm{~mA}$, the power switches $M_{N}$ and $M_{P}$ and the PWM block used in the SI converter are turned off for the micro switched-capacitor converter ( $\mu$-SCC) mode with operation phases $\Phi_{1}$ and $\Phi_{2}$ without using the inductor. In this case, the large compensator capacitor $C_{C}$ adopted for the stability of PWM in the SI converter is reused as a flying capacitor. For a given $C_{C}$ and switching frequency, ultralight load current rage is determined as the higher efficient region than that of DCM operation. Therefore, owing to the capacitor sharing concept, even if two converter topologies are used as SI and SC converters, there is no additional size requirement for capacitors. Furthermore, as shown in Figure 4 , the converter in $\mu$-SCC mode transfers the power to the output only when the output voltage $\left(V_{O}\right)$ is lower than the reference voltage $\left(V_{R E F}\right)$. Then, the controller loss can be reduced because the feedback control loop can use only a hysteresis comparator without any complex control circuitry. Therefore, the proposed triple-mode SIC converter, which operates in the CCM, DCM, and $\mu$-SCC mode, can achieve high efficiency over the entire load current range by changing the operating mode according to the load current conditions.

Table 1. Operation regions of the triple mode SIC dc-dc buck converter.

\begin{tabular}{cc}
\hline Load Current Rating & Operation Principle \\
\hline$>20 \mathrm{~mA}$ (Heavy load) & CCM with PWM (SI) \\
$2-20 \mathrm{~mA}$ (Light load) & DCM with VFM (SI) \\
$<2 \mathrm{~mA}$ (Ultralight load) & $\mu-S C C$ \\
\hline
\end{tabular}




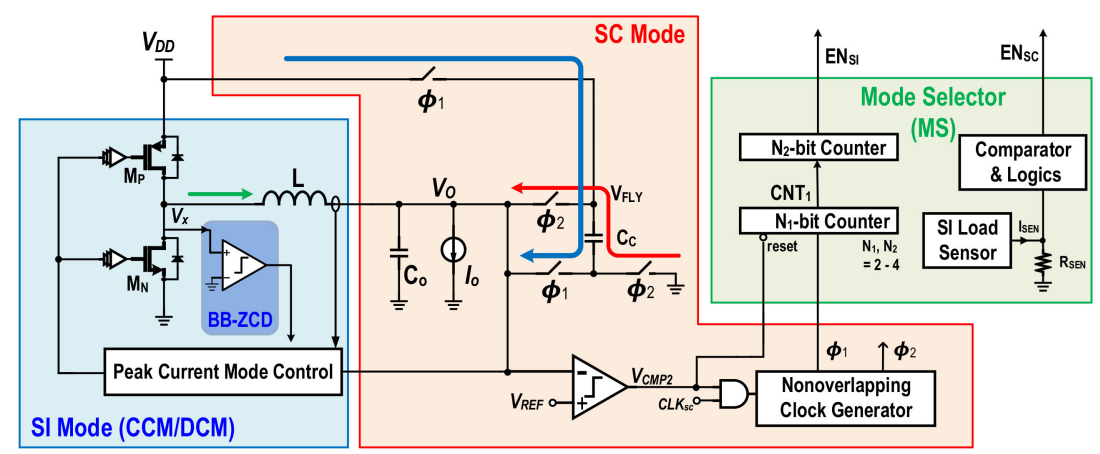

Figure 3. Overall architecture of the proposed triple-mode SIC dc-dc buck converter.

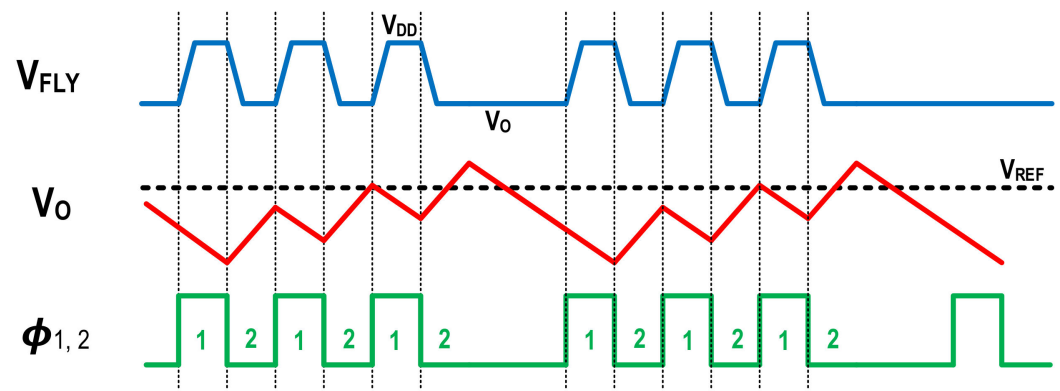

Figure 4. Operation of the proposed SIC converter in the micro switched-capacitor converter $(\mu$-SCC) mode.

For automatic selection of the operation mode, the converter should sense the load current. The MS determines the operation mode as shown in Figure 3. When the converter operates as an SI converter, the load current can be sensed and the mode can be easily switched to another mode owing to the use of an inductor-current-sensing network and the ZCD block in SI converter. However, when the converter operates as the $\mu$-SCC mode, since most of the power hungry blocks are turned off, a load current sensor with low power consumption is required. To reduce the static power loss, the MS uses a digital counter for the load current sensor, which is newly proposed here. Figure 5 shows the output voltage $V_{O}$, load current $I_{O}$, output of the $N_{1}$-bit counter $\mathrm{CNT}_{1}$, and an enable signal for the SI converter $E N_{S I}$ as an example for a mode transition from the $\mu$-SCC mode to the SI converter.
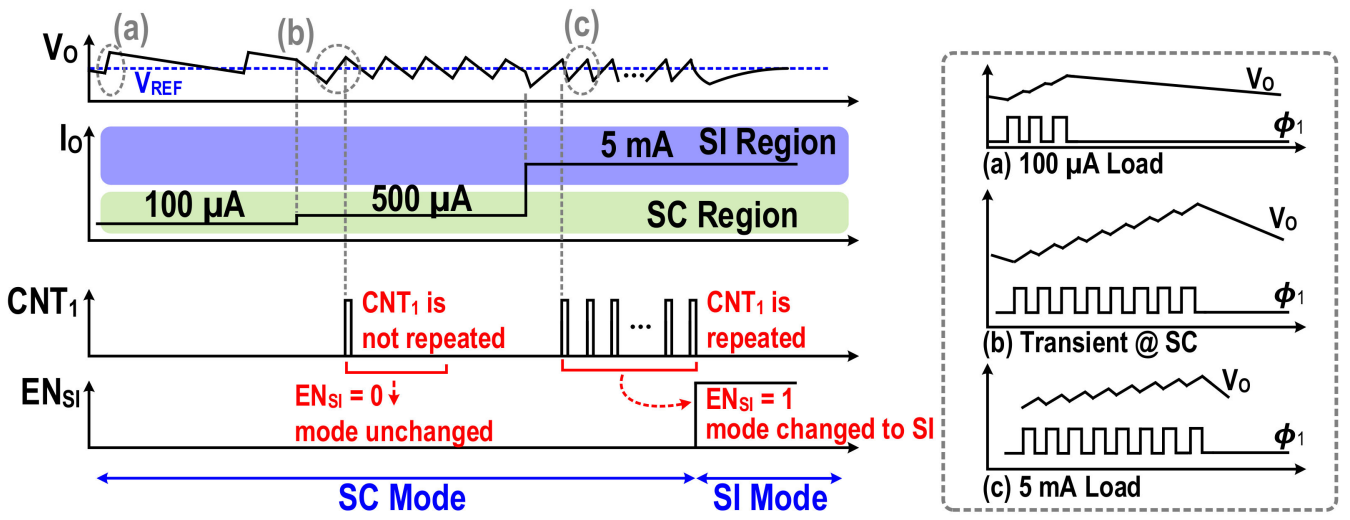

Figure 5. Digital counter method for the load current transition cases in $\mu$-SCC mode.

For the $\mu$-SCC mode operation, the principle of charge conservation at both $\Phi_{1}$ and $\Phi_{2}$ should be satisfied:

$$
\begin{gathered}
V_{O 1} C_{O}+\left(V_{D D}-V_{O 1}\right) C_{C}=V_{O 2}\left(C_{C}+C_{O}\right) \\
V_{O 2}-V_{O 1}=\frac{C_{C}}{C_{O}}\left(V_{D D}-V_{O 1}-V_{O 2}\right)
\end{gathered}
$$


where $V_{O 1}, V_{O 2}$, and $V_{D D}$ are the output voltage at $\Phi_{1}$ and $\Phi_{2}$, and the supply voltage, respectively. The ripple voltage $\left(V_{O_{2}}-V_{O 1}\right)$ can be obtained from the relationship between the load current $I_{O}$ and switching period $T_{S W}$ as follows:

$$
V_{O 2}-V_{O 1}=\frac{I_{O}}{C_{O}} \frac{T_{S W}}{2}
$$

Substituting Equation (2) into Equation (3) gives

$$
I_{O} \frac{T_{S W}}{2}=C_{C}\left(V_{D D}-V_{O 1}-V_{O 2}\right)
$$

Since the sum of $V_{O 1}$ and $V_{O 2}$ is twice the average output voltage $V_{O}$ in the steady state, we can write

$$
I_{O} \frac{T_{S W}}{2} \frac{1}{C_{C}}=V_{D D}-2 V_{O}
$$

This expression can be rewritten by including the switching frequency $f_{S W}$ for the load current:

$$
I_{O}=4\left(\frac{V_{D D}}{2}-V_{O}\right) C_{C} f_{S W}
$$

From Equation (6), it is evident that as the load increases, the switching frequency in the operation phases $\left(\Phi_{1}\right.$ and $\left.\Phi_{2}\right)$ of the $\mu$-SCC mode also increases. Therefore, counting the number of $\Phi_{1}$ pulses $\left(N_{1}\right)$ by using the $N_{1}$-bit counter $C N T_{1}$ can indicate whether the load current level reaches a certain threshold. Furthermore, an $\mathrm{N}_{2}$-bit counter is introduced to determine whether the mode change from the $\mu$-SCC mode to the SI converter in DCM is required or not when a load current transition occurs. The $E N_{S I}$ becomes high only when $C N T_{1}$ pulsates $2 N_{2}$ times repeatedly. Such pulsation implies that the load current is high for a sufficiently long time, and it indicates that the mode should be changed to the SI converter. By contrast, for a small load current transition in the $\mu$-SCC mode, since the $C N T_{1}$ toggles only once or twice, resulting in maintaining $E N_{S I}$ in low level. Through this digital counter method, it can be determined whether a mode change from the $\mu$-SCC mode to the SI converter in DCM should occur.

\section{BB-ZCD for DCM}

Figure 6 shows that when the load current in the SI converter decreases from a heavy load current to a light load current, it induces a reverse inductor current. For the prevention of this reverse current, the accurate ZCD is essential for the DCM. In general, the switching node $V_{X}$ is monitored for the $Z C D$. This is because when a reverse current flows during the on time of the switch $M_{N}$, the polarity of $V_{X}$ changes from a negative voltage to a positive voltage. Therefore, zero current detection is possible by comparing the ground voltage with the $V_{X}$ voltage by using a comparator. However, as shown in Figure 6, the conventional ZCD has the drawbacks of a delay, an offset, limited gain of the comparator, logic delay, and gate driver delay, rendering the ZCD incapable of determining the point where $V_{X}$ is exactly zero. Figure 7 shows a common-gate comparator is mainly adopted in the conventional ZCD to compare $V_{X}$ with the ground voltage. However, if there is a delay and an offset in the comparator, it is difficult to realize a high-precision ZCD. This results in the flow of a reverse inductor current, which reduces the efficiency of the converter.

To solve the aforementioned problems, this paper proposes a BB-ZCD with a DCM controller involving autocalibration scheme through the gate signal $\left(V_{G N}\right)$ of $M_{N}$, as shown in Figure 8 . The falling edge of $V_{G N}$ is used as the clock signal of the latched comparator for digital feedback. 


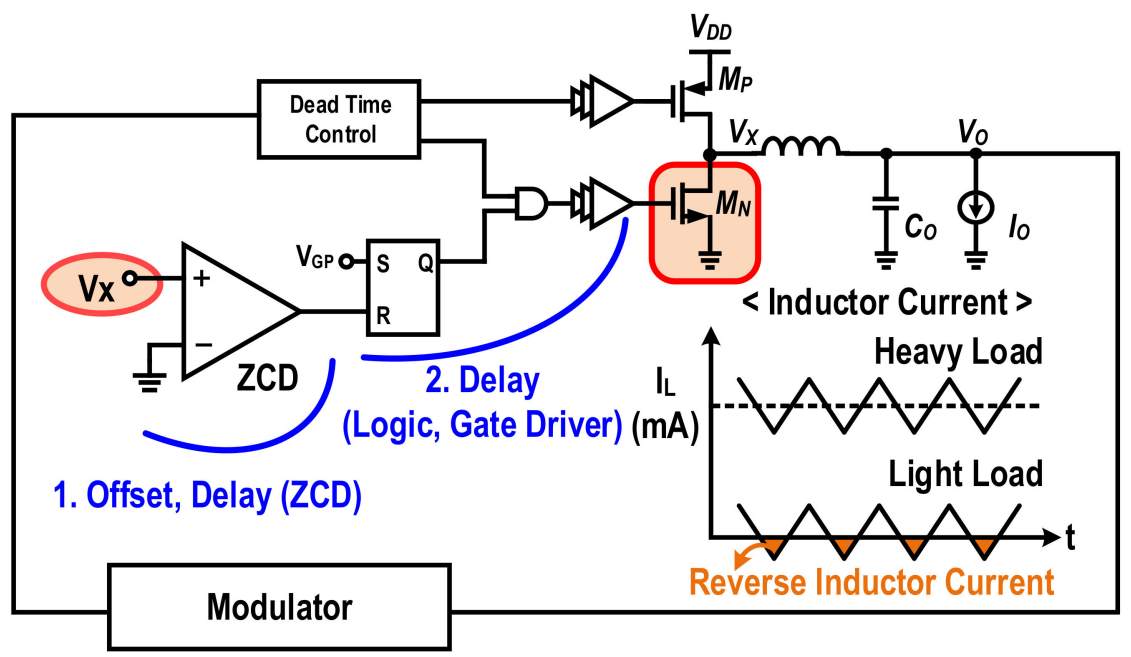

Figure 6. Zero current detection issues in conventional dc-dc buck converter.

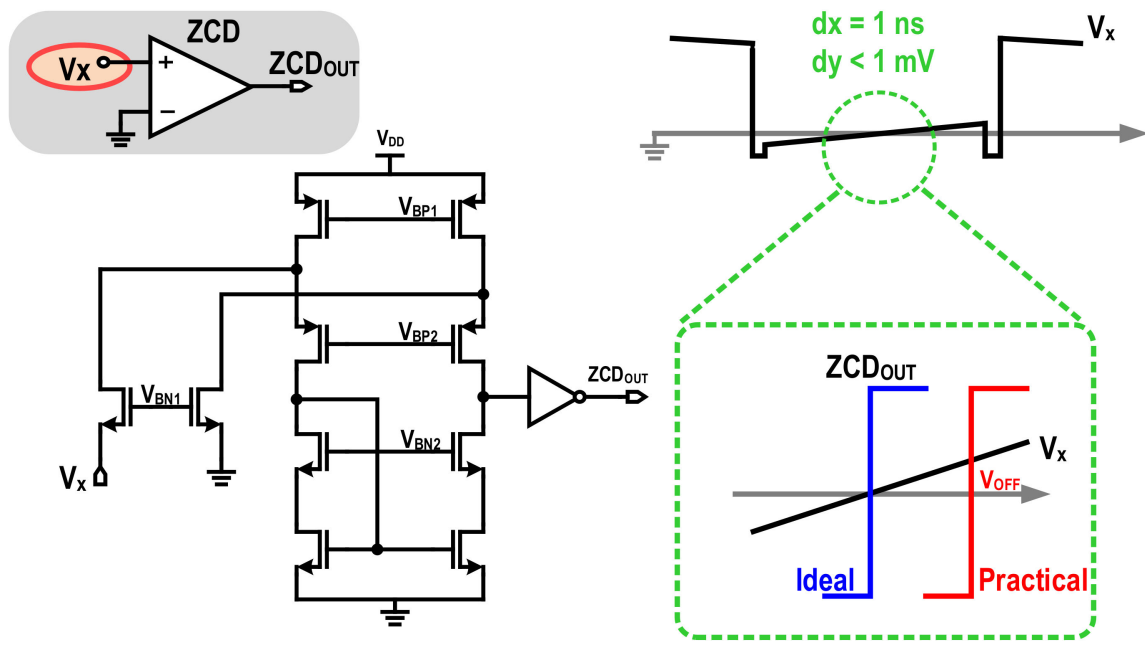

Figure 7. Common-gate comparator for conventional zero current detector.

The latched comparator determines whether the polarity of the switching node $V_{X}$ is positive or negative when the $V_{G N}$ becomes low. If the falling edge of $V_{G N}$ is positioned after the actual zero-crossing point of $V_{X}$, the output of the latched comparator becomes high, and the output code of the shift register increases. This up-counted output code increases the width of the sinking transistor $\left(M_{N T}\right)$ in the comparator, resulting in the falling edge of $V_{G N}$ occurring earlier in the next period. By contrast, if the falling edge of $V_{G N}$ is positioned before the actual zero-crossing point of $V_{X}$, the output of the latched comparator becomes zero, and the output code of the shift register is down-counted. This reduces the width of $M_{N T}$. Consequently, the $V_{G N}$ pulse becomes low at a later instant compared to the previous period. In other words, the latched comparator monitors whether the falling edge of $V_{G N}$ occurs before or after the actual zero-crossing time of $V_{X}$ and adjusts the sinking strength of the common gate comparator so that $V_{G N}$ converges to the optimal time while the shift register code converges to $[k: k+1]$. Therefore, the digital feedback facilitates accurate zero current detection in the DCM.

However, a practical error factor in the latched comparator can cause a problem in the ZCD. If there is an offset in the latched comparator, the $V_{G N}$ pulse eventually converges when $V_{X}$ equals its offset voltage, not the ground level. Accordingly, the amount of offset acceptable in the latched comparator should be determined. Since the slope of $V_{X}$ in our implementation is less than $1 \mathrm{mV} / \mathrm{ns}$, if the offset exceeds $20 \mathrm{mV}$, similar to the offset in the conventional latched comparator, a considerable delay is introduced. For an allowable delay of 2 to $5 \mathrm{~ns}$, the offset should be lower than several 
millivolts. Therefore, the latched comparator in Figure 9 is adopted for ensuring a low offset [14]. It has two operation phases, one for calibration $(\mathrm{Cal})$ and the other for comparison $\left(\mathrm{Cal}_{b}\right)$. In the calibration phase, the two input nodes of the comparator are shorted to the ground, and the bias voltage $\left(V_{c a l}\right)$ is adjusted to minimize its offset. If calibration is performed only once at the start-up time, the discharge of the calibration capacitor $\left(C_{c a l}\right)$ at a later time would change $V_{c a l}$. Therefore, it is necessary to calibrate the offset periodically. For periodic calibration, the calibration phase is applied during the on time of the high side switch $M_{P}$ because the BB-ZCD does not work during this phase. Thus, a high-precision $\mathrm{BB}-\mathrm{ZCD}$ can be realized by using this low-offset latched comparator.
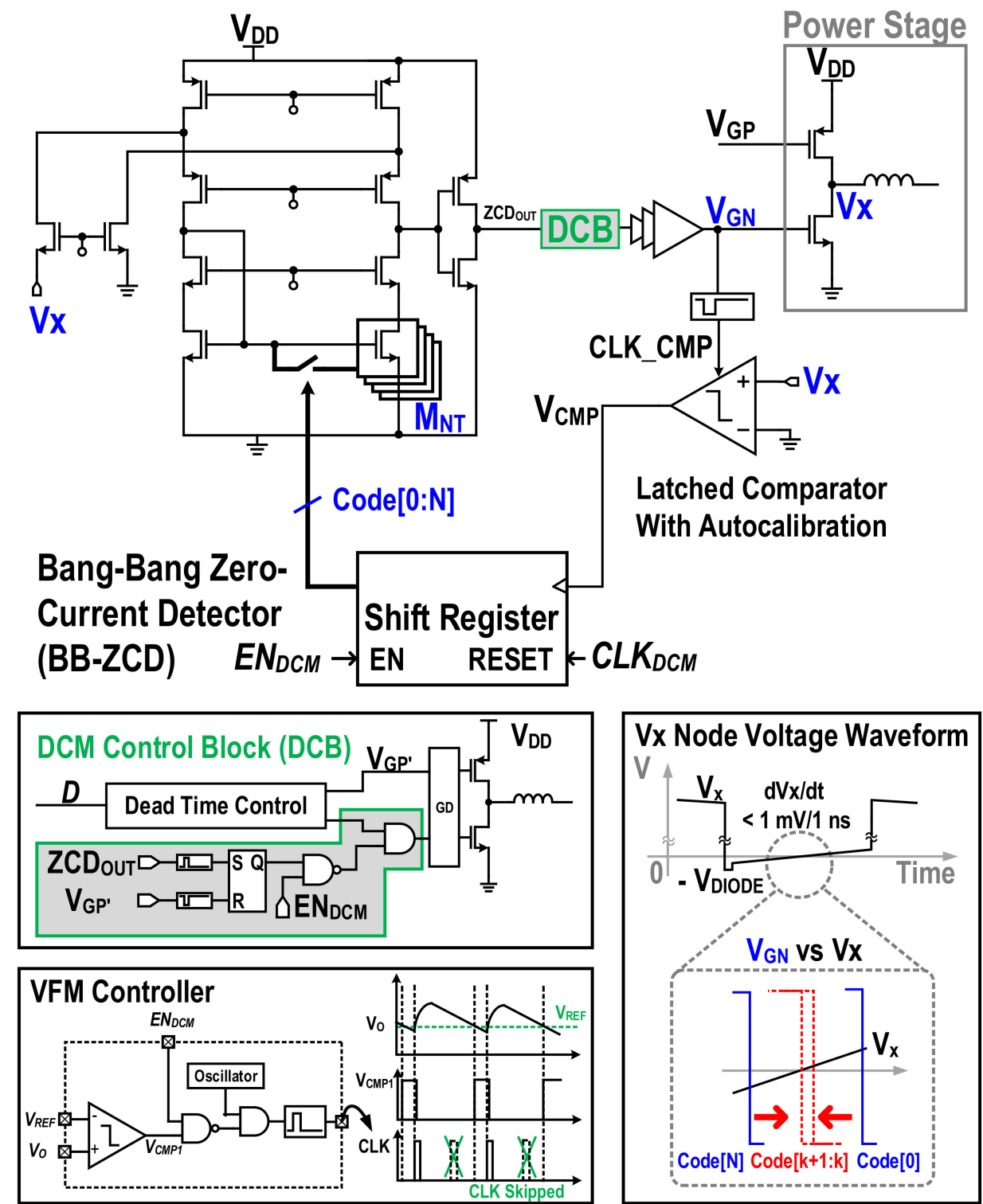

Figure 8. Proposed the bang-bang zero current detector (BB-ZCD) and discontinuous conduction mode (DCM) controllers.

Figure 8 also shows the implementation of the clock skipping scheme to adjust the switching frequency for VFM control in the DCM. If there is no clock skipping, the output voltage $V_{O}$ will saturate because of the unnecessary switching. Therefore, clock skipping is necessary to ignore the clock signal until $V_{O}$ is less than $V_{R E F}$. The VFM control involving this clock skipping not only prevents the divergence of $V_{O}$ in the DCM but also reduces switching loss. Figure 10 shows simulation results for $L=4.7 \mu \mathrm{H}, C_{O}=4.7 \mu \mathrm{F}, V_{D D}=3.7 \mathrm{~V}, V_{O}=1.8 \mathrm{~V}$, and $I_{O}=10 \mathrm{~mA}$. 


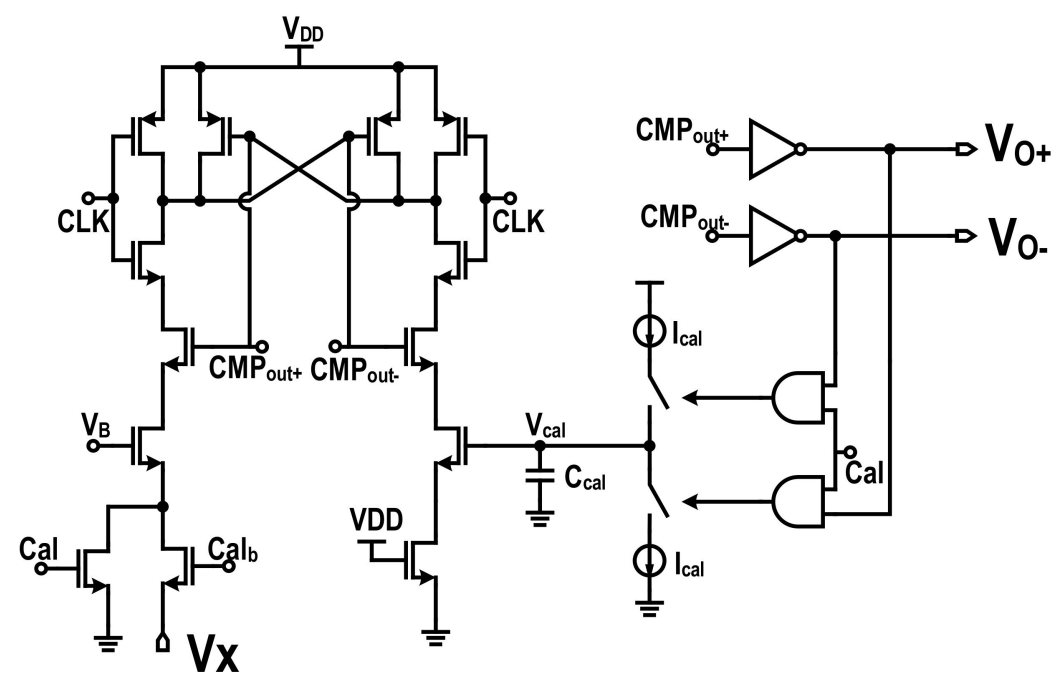

Figure 9. Low offset latched comparator.

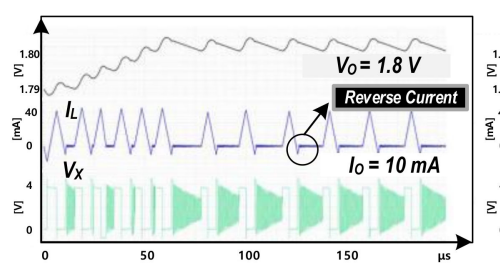

(a)

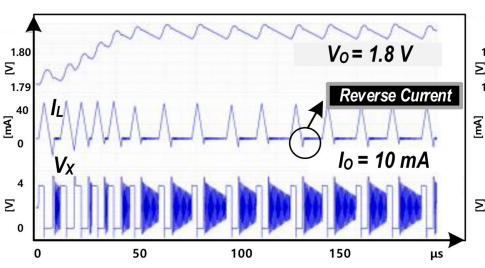

(b)

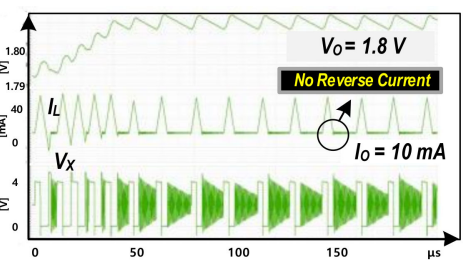

(c)

Figure 10. Simulation results of the proposed triple-mode SIC converter in DCM with (a) the conventional ZCD, (b) the BB-ZCD with uncalibrated offset, and (c) the BB-ZCD with calibrated offset.

Figure 10a corresponds to the case of the SI converter operating in the DCM and equipped with the conventional ZCD. Despite $V_{O}$ being well regulated to $1.8 \mathrm{~V}$, a reverse inductor current flows, resulting in low power conversion efficiency. Figure $10 \mathrm{~b}$ shows the simulation result for the SI converter in the DCM, using the proposed BB-ZCD. The offset of the latched comparator is $10 \mathrm{mV}$, and it is not calibrated. Although $V_{O}$ is well regulated to $1.8 \mathrm{~V}$, a reverse inductor current also occurs. This is because the code of the shift register converges to a point where $V_{X}$ equals the offset of the latched comparator. In this simulation result, the output code of the shift register converged to code [2: 3]. Figure 10c shows the simulation result when the offset of the latched comparator is calibrated. The reverse inductor current gradually disappears since the inaccuracy of ZCD is progressively reduced. Finally, a regulated output and absence of a reverse inductor current are observed in the steady state. At this time, the output code converges to code [5: 6].

\section{Measurement Results}

The proposed triple-mode SIC converter was fabricated in a $0.18 \mu \mathrm{m}$ CMOS process, and the die area was $0.495 \mathrm{~mm}^{2}$, as shown in Figure 11. The supply voltage $V_{D D}$ was $3.7 \mathrm{~V}$, the output voltage $V_{O}$ ranged from 1.2 to $1.8 \mathrm{~V}$, and the load current ranged from $100 \mu \mathrm{A}$ to $500 \mathrm{~mA}$. The inductance and capacitance of the power filter were $4.7 \mu \mathrm{H}$ and $4.7 \mu \mathrm{F}$, respectively.

Figure 12a shows waveforms of the output voltage $V_{O}$, switching node voltage $V_{X}$, and inductor current $I_{L}$ for a load current $I_{O}$ of $100 \mathrm{~mA}$ and operation in the CCM with a fixed switching frequency of $1 \mathrm{MHz}$. Figure 12b shows the measurement results for a $10 \mathrm{~mA}$ load current and DCM operation. The reverse inductor current is eliminated owing to the high-precision BB-ZCD. Figure 13a shows the waveforms of the $V_{O}$ and top plate voltage of $C_{C}\left(V_{F L Y}\right)$ for a load current of $200 \mu \mathrm{A}$ and operation in the $\mu$-SCC mode when the $C_{C}$ value of $1 \mathrm{nF}$ is adopted in this paper. It can be seen that the proposed converter operates in the $\mu$-SCC mode only when powering is required. Figure $13 \mathrm{~b}$ shows the load 
transient response in the $\mu$-SCC mode when the load current varies between 0 and $2 \mathrm{~mA}$. The MS can maintain the $\mu$-SCC mode since the load current is still in the $\mu$-SCC mode region.

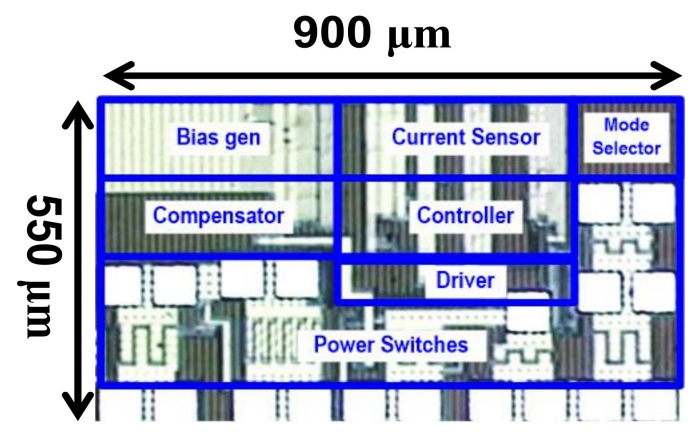

Figure 11. Chip micrograph.

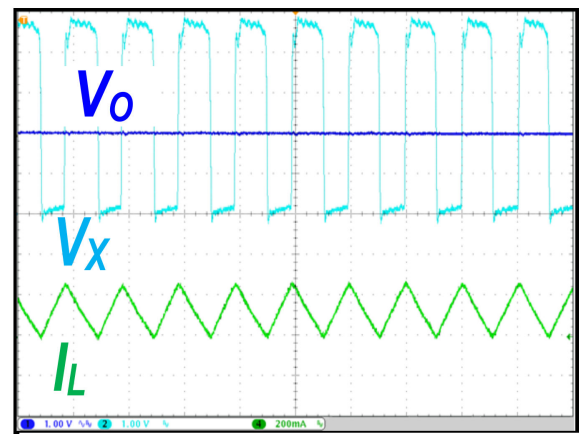

CCM Mode $I_{0}=100 \mathrm{~mA}$

(a)

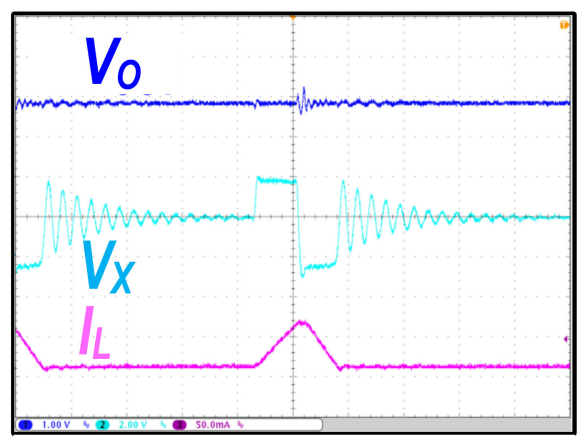

DCM Mode $10=10 \mathrm{~mA}$

(b)

Figure 12. Measurement of steady-state waveforms in the SI converter with (a) CCM and (b) DCM for $V_{D D}=3.7 \mathrm{~V}$ and $V_{O}=1.8 \mathrm{~V}$.

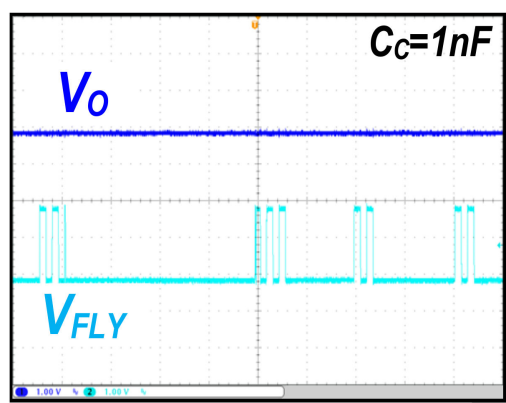

$\mu$-SCC Mode, $I_{0}=1 \mathrm{~mA}$

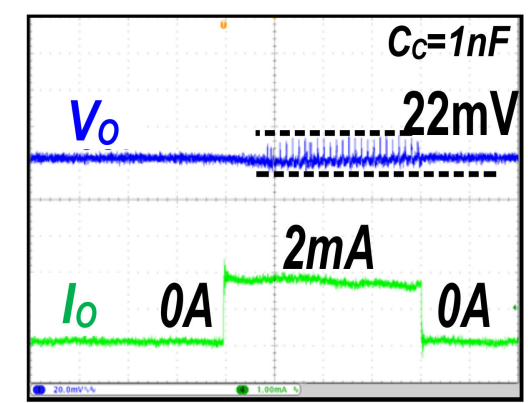

Transient Response in $\mu$-SCC Mode

(a)

(b)

Figure 13. Measurement of (a) steady-state waveforms and (b) transient response in $\mu$-SCC mode for $V_{D D}=3.7 \mathrm{~V}$ and $V_{O}=1.8 \mathrm{~V}\left(C_{C}=1 \mathrm{nF}\right)$.

Figure 14 shows the power conversion efficiency plot of the triple-mode SIC dc-dc buck converter for the load current range from $60 \mu \mathrm{A}$ to $400 \mathrm{~mA}$, a $3.7 \mathrm{~V}$ supply, and an output voltage of $1.8 \mathrm{~V}$. The maximum efficiency is $94.5 \%$ at the load current of $60 \mathrm{~mA}$ in the CCM. Furthermore, it delivers over $85 \%$ efficiency in the load current range from $100 \mu \mathrm{A}$ to $300 \mathrm{~mA}$. Table 2 shows a comparison of the proposed converter with state-of-the-art dc-dc buck converters for light load conditions. The proposed converter shows higher efficiency than the other converters owing to mode transition among the CCM, DCM, and $\mu$-SCC mode. In particular, the load current range for which the efficiency exceeds $85 \%$ is considerably wider in the proposed converter. 


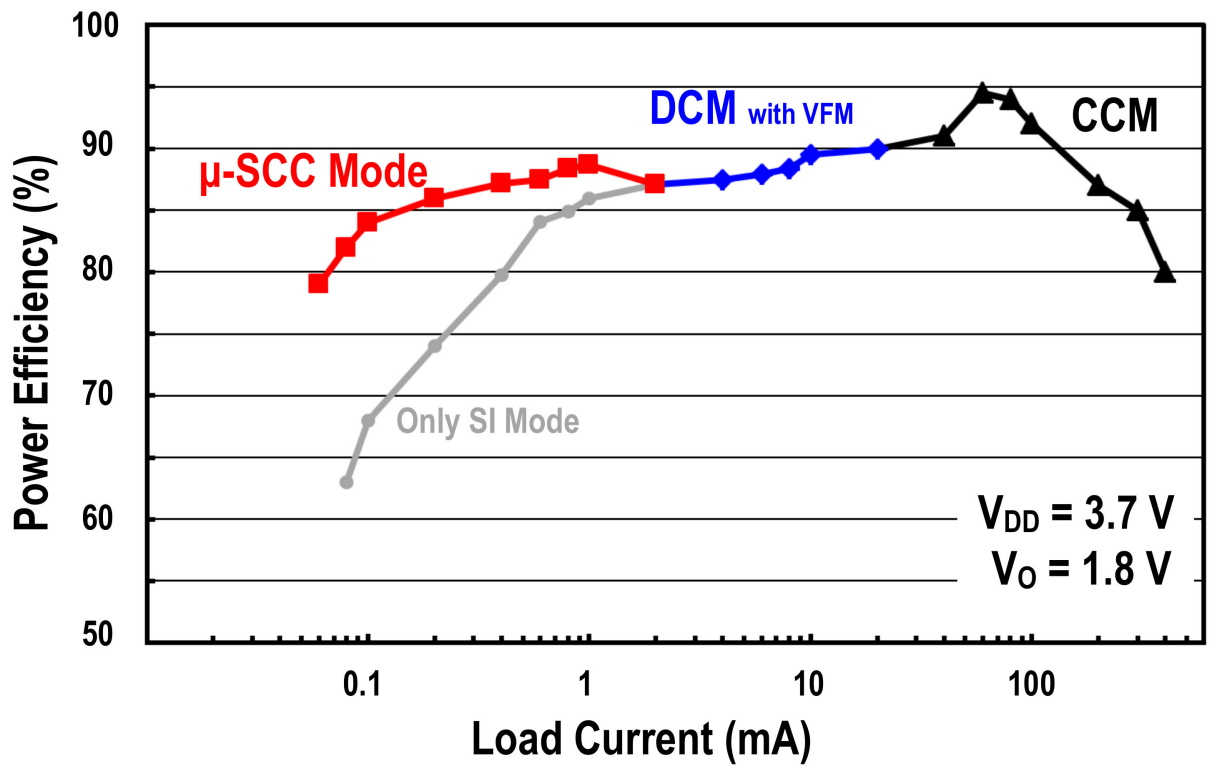

Figure 14. Measured efficiency plot versus the load current with $V_{D D}=3.7 \mathrm{~V}$ and $V_{O}=1.8 \mathrm{~V}$.

Table 2. Performance comparison table.

\begin{tabular}{|c|c|c|c|c|c|}
\hline & This Work & [1] & [2] & [5] & [7] \\
\hline Technology & $0.18 \mu \mathrm{m}$ CMOS & $0.35 \mu \mathrm{m}$ CMOS & $0.35 \mu \mathrm{m}$ CMOS & $45 \mathrm{~nm}$ CMOS & $0.18 \mu \mathrm{m}$ CMOS \\
\hline Input voltage & $3.0-4.2 \mathrm{~V}$ & $1.8-3.0 \mathrm{~V}$ & $2.7-5.0 \mathrm{~V}$ & $2.8-4.2 \mathrm{~V}$ & $2.3-3.3 \mathrm{~V}$ \\
\hline Output voltage & $1.2-1.8 \mathrm{~V}$ & $0.9 \mathrm{~V}$ & $1 \mathrm{~V}$ & $0.6-1.2 \mathrm{~V}$ & $1 \mathrm{~V}$ \\
\hline Control Scheme & $\begin{array}{l}\text { SI (Heavy load) } \\
\text { SC (Light load) }\end{array}$ & ASFPWM * & PWM/PFM & PWM/PFM & PWM \\
\hline Switching frequency & $1 \mathrm{MHz} @ \mathrm{CCM}$ & $\begin{array}{c}250 \mathrm{kHz} / 500 \mathrm{kHz} / \\
1 \mathrm{MHz} / 2 \mathrm{MHz}\end{array}$ & $0.5-1 \mathrm{MHz}$ & - & $0.96 \mathrm{MHz}$ \\
\hline LC filter & $\begin{array}{l}L=4.7 \mu \mathrm{H} \\
C=4.7 \mu \mathrm{F}\end{array}$ & $\begin{array}{l}L=2.2 \mu \mathrm{H} \\
C=2.2 \mu \mathrm{F}\end{array}$ & $\begin{array}{l}L=10 \mu \mathrm{H} \\
C=10 \mu \mathrm{F}\end{array}$ & $\begin{array}{c}L=10 \mu \mathrm{H} \\
C=2 \mu \mathrm{F}\end{array}$ & $\begin{array}{l}L=6.8 \mu \mathrm{H} \\
C=1.2 \mu \mathrm{F}\end{array}$ \\
\hline Max. Efficiency & $94.5 \%$ & $90 \%$ & $90 \%$ & $87.4 \%$ & $86.5 \%$ \\
\hline $\begin{array}{c}\text { Load range } \\
\text { over } 85 \% \text { PCE ** }\end{array}$ & $\begin{array}{c}100 \mu \mathrm{A} \text { to } 300 \\
\mathrm{~mA}\end{array}$ & $70-500 \mathrm{~mA}$ & $70-500 \mathrm{~mA}$ & $1-80 \mathrm{~mA}$ & $1-4 \mathrm{~mA}$ \\
\hline
\end{tabular}

\section{Conclusions}

As the popularity of smart and wearable devices has recently increased, the overall power conversion efficiency of PMIC has become very important. Therefore, this paper proposes a triple-mode SIC dc-dc buck converter with reusable flying capacitors operating in CCM, DCM, and $\mu$-SCC modes. High power conversion efficiency can be achieved over a wide load current range. In particular, $\mu$-SCC mode is controlled by a single comparator and MS is based on a digital counter to minimize controller loss. In addition, the proposed BB-ZCD can accurately detect the zero crossing point of the inductor current based on simple digital feedback and operate efficiently in DCM. The proposed buck converter has achieved efficiencies of exceeding $85 \%$ over a wide load current range of $100 \mu \mathrm{A}$ to $300 \mathrm{~mA}$, which extends battery time in IoT applications.

Author Contributions: Conceptualization, J.B.; Methodology, J.B.; Validation, J.B. and S.-U.S.; Formal Analysis, J.B.; Investigation, J.B.; Resources, J.B.; Data Curation, J.B.; Writing-Original Draft Preparation, S.-U.S.; Writing-Review \& Editing, S.-U.S.; Visualization, S.-U.S.; Supervision, S.-U.S.; Project Administration, H.-M.L.; Funding Acquisition, H.-M.L. All authors have read and agreed to the published version of the manuscript.

Funding: The present research was supported by the research fund of Dankook University in 2019.

Conflicts of Interest: The authors declare no conflicts of interest. 


\section{References}

1. Man, T.Y.; Mok, P.K.; Chan, M. An auto-selectable-frequency pulse-width modulator for buck converters with improved light-load efficiency. In Proceedings of the 2008 IEEE International Solid-State Circuits Conference (ISSCC), San Francisco, CA, USA, 3-7 February 2008; pp. 440-441.

2. Liou, W.; Yeh, M.; Kuo, Y.L. A High Efficiency Dual-Mode Buck Converter IC for Portable Applications. IEEE Trans. Power Electron. 2008, 23, 667-677. [CrossRef]

3. Lin, J.-Y.; Hsu, Y.-C.; Lin, Y.-D. A Low EMI DC-DC Buck Converter with a Triangular Spread-Spectrum Mechanism. Energies 2020, 13, 856. [CrossRef]

4. Cho, Y.-K.; Park, B.H.; Hyun, S.-B. Delta-Sigma Modulator-Based Step-Up DC-DC Converter with Dynamic Output Voltage Scaling. Electronics 2020, 9, 498. [CrossRef]

5. Bandyopadhyay, S.; Ramadass, Y.K.; Chandrakasan, A.P. $20 \mu \mathrm{A}$ to $100 \mathrm{~mA}$ DC-DC converter with 2.8 to $4.2 \mathrm{~V}$ battery supply for portable applications in $45 \mathrm{~nm}$ CMOS. In Proceedings of the 2011 IEEE International Solid-State Circuits Conference (ISSCC), San Francisco, CA, USA, 20-24 February 2011; pp. 386-388.

6. Park, S.; Cho, J.; Lee, K.; Yoon, E. 12.3 PWM buck converter with $>80 \%$ PCE in $45 \mu$ A-to-4 mA loads using analog-digital hybrid control for implantable biomedical systems. In Proceedings of the 2015 IEEE International Solid-State Circuits Conference (ISSCC), San Francisco, CA, USA, 22-26 February 2015; pp. 1-3.

7. Mulligan, M.D.; Broach, B.; Lee, T.H. A $3 \mathrm{MHz}$ Low-Voltage Buck Converter with Improved Light Load Efficiency. In Proceedings of the 2007 IEEE International Solid-State Circuits Conference (ISSCC), San Francisco, CA, USA, 11-15 February 2007; pp. 528-620.

8. Navidi, M.M.; Graham, D.W. A Regulated Charge Pump with Extremely Low Output Ripple. Electronics 2019, 8, 1293. [CrossRef]

9. Ballo, A.; Grasso, A.D.; Palumbo, G. A Review of Charge Pump Topologies for the Power Management of IoT Nodes. Electronics 2019, 8, 480. [CrossRef]

10. Choi, M.; Jeong, D.-K. Design of Soft-Switching Hybrid DC-DC Converter with 2-Phase Switched Capacitor and $0.8 \mathrm{nH}$ Inductor for Standard CMOS Process. Electronics 2020, 9, 372. [CrossRef]

11. El-Damak, D.; Bandyopadhyay, S.; Chandrakasan, A.P. A 93\% efficiency reconfigurable switched-capacitor DC-DC converter using on-chip ferroelectric capacitors. In Proceedings of the 2013 IEEE International Solid-State Circuits Conference (ISSCC), San Francisco, CA, USA, 17-21 February 2013; pp. 374-375.

12. Salem, L.G.; Mercier, P.P. 4.6 An 85\%-efficiency fully integrated 15-ratio recursive switched-capacitor DC-DC converter with 0.1-to-2.2 V output voltage range. In Proceedings of the 2014 IEEE International Solid-State Circuits Conference (ISSCC), San Francisco, CA, USA, 9-13 February 2014; pp. 88-89.

13. Baek, J.; Lee, J.; Shin, S.; Jung, M.; Cho, G. Switched inductor capacitor buck converter with $>85 \%$ power efficiency in $100 \mathrm{uA}$-to-300 mA loads using a bang-bang zero-current detector. In Proceedings of the 2018 IEEE Custom Integrated Circuits Conference (CICC), San Diego, CA, USA, 8-11 April 2018; pp. 1-4.

14. Masaya, M.; Yusuke, A.; Daehwa, P.; Akira, M. A low-noise self-calibrating dynamic comparator for high-speed ADCs. In Proceedings of the 2008 IEEE Asian Solid-State Circuits Conference (ASSCC), Fukuoka, Japan, 3-5 November 2008; pp. 269-272.

(C) 2020 by the authors. Licensee MDPI, Basel, Switzerland. This article is an open access article distributed under the terms and conditions of the Creative Commons Attribution (CC BY) license (http://creativecommons.org/licenses/by/4.0/). 